\title{
TRUST AND REPUTATION SYSTEMS IN TWO ONLINE AUCTION AND SHOPPING WEBSITES FROM ROMANIA AND THE NETHERLANDS
}

\author{
POPA, D[iana] M[ariana] \& NICA COTET, G[abriela] B[eatrice]
}

\begin{abstract}
Online customer-to-customer auction websites are characterised by information asymmetry. The use of a positive or a negative reputation system in such a medium indicates the level of generalized trust of the residents of that country. In this sense, we want to underline the connection between the level of generalized trust in Romania and the Netherlands and the way the two most popular auction web-sites in these countries function as found in the online participatory observation conducted. Based on a background of low generalized trust in Romania, individuals who interact on auction websites require a type of assurance such as public reputation while in the Netherlands, based on a higher level of generalized trust, transactions from customer - to - customer auction websites take place in the absence of such assurances.

Keywords: generalized trust, reputation system, information asymmetry, online auction
\end{abstract}

\section{INTRODUCTION}

Trust is needed precisely where it is difficult for it to be obtained: in unstable environments, characterized by information asymmetry (Yamagishi, 2011) [6]. Such an environment is represented by the online auction and shopping websites. These are characterized by information asymmetry, in the sense that it is difficult or impossible to judge the quality of a certain good before you buy it. Yamagishi (2011) explains how in the process of cooperation, uncertainty arises from incomplete/limited knowledge of the individual, from "information asymmetry" [6]. If those involved in the cooperation process do not engage in that certain relation of social uncertainty (information asymmetry) in interactions based on trust (in the absence of formal assurances) cooperation cannot occur (Kollock, 1994, Yamagishi, 2011) [3], [6]. The lack of monitoring possibility of the others actions means that the individual entering the cooperation relationship assumes a risk. Yamagishi (2011) [6] better explains what this asymmetry means using the now classical studies of Akerlof (1970 apud Yamagishi, 2011) [6] about the second hand car market (which he names the "lemon market") and the study of Kollock (1994) [3] about the rise and rubber markets from Asia. We will shortly present these two studies in the following in order to clarify the concept of information asymmetry which also characterises the customer-to-customer auction websites.

\section{INFORMATION ASYMMETRY}

The second hand car market is characterized by information asymmetry between buyers and sellers, i.e. the seller knows the problems of the car he is selling, while the buyer does not know them and cannot assess on the spot. The buyer will know these problems only after purchasing and using the car. Realizing that the car may have such hidden defects, the buyer takes this into account when negotiating a price with the seller. The buyer who knows he cannot recognize any defects will not pay a high price for such a car if he does not trust the seller. The seller in turn would have a small profit if he sold a good car (the price received would be closer to the actual value of the car) and have a high profit if they sold a "lemon" (the price paid by the buyer for a car hidden defects is higher than the actual value of the car) (Akerlof, 1970 apud Yamagishi, 2011) [6].

The word lemon refers to a car with hidden problems that the buyer immediately cannot asses when he buys the car. The behaviour of the seller increases the probability that the second hand car market will have many "lemons" because they will bring the greatest profit for the seller immediately. On the other hand, the buyer will be more cautious about the possibility of actually buying a "lemon" and will be willing to pay increasingly less. In time such behaviour is detrimental to both parties, leading to an undesirable situation which can be avoided if buyers come to trust sellers (Akerlof, 1970 apud Yamagishi, 2011) [6].

In the second study we find exemplified two different markets in regard to the level of information available between partners. Kollock (1994) [3] highlights an interesting difference between the market for rubber and the market for rice in Asia: if the first one is open (goods are traded freely among strangers) in the second, in order to trade goods, commitment relationships are formed (rubber trade occurs between specific partners). This difference is attributed to the level of social uncertainty involved in the two markets due to the fact that the quality of goods cannot be estimated in the same way: the quality of rice can be observed with the naked eye but the quality rubber cannot, requiring the material to be processed in order to observe if it is good or not. For the rubber buyers there is the risk of buying inferior quality material. The buyers of rice are not threatened by this risk because the product's quality can be known by simple observation. This comparison means that the level of social uncertainty involved in buying rubber is higher than the one in buying rice. As in the market of second hand cars in these conditions, if there is no trust, buyers are not willing to offer a higher price for rice and sellers are discouraged to invest time and energy in producing a quality good because it would increase the price of the good Kollock (1994) [3].

In free markets, such as that of rice from the example of Kollock (1994) [3] buyers and sellers find each other 
and exchange goods quickly. Easy evaluation of the quality of goods exchanged allows them to establish a price and conclude the transaction quickly. In online auction websites this is not possible. Yamagishi \& Matsuda (2002) [7] show how online auctions are similar in degree of information asymmetry with the rubber and the second hand car markets: buyers cannot observe directly the quality of goods they exchange and cannot directly control the behavior of interacting partners. Due to the difficulty of assessing the product's quality, the online auction websites are similar to the second hand car market from the example of Akerlof (1970) and with the rubber market from the example of Kollock (1994) [3]. Solutions for cooperation in such situations of information asymmetry/social uncertainty are: generalized trust; developing a public reputation; developing a commitment relationship. However, due to the fact that most online buyers are not in search of only one sort of product the last solution is less likely to apply here.

\section{DELIMITATION OF THE CONCEPT OF TRUST}

Trust is both an attracting and a difficult concept to pin down in the social sciences. There are numerous approaches to trust, ranging from economic, psychological, cultural or sociological. We decided to stop here upon a holistic approach on trust, represented by the works of Yamagishi $(2002,2011)$ [6], [7] and Cook (Cook et al., 2005) [1]. Yamagishi includes in his theory all the main aspects of the perspectives on the concept of trust (such as generalized trust, specific trust, assurance, risk, reputation, etc.) building a complex theory that carefully distinguishes between different shades of the relational concepts of the trust thematic.

Trust is an alternative solution to formal arrangements of ensuring cooperation (Cook et al., 2005) [1] and manifests itself in situations of risk defined as information asymmetry (Yamagishi, 2011) [6]. Likewise, Ouchi (1979) believes that "individuals should be able to trust each other or to closely monitor each other in order to cooperate" [4]. Generalized trust (saying "I believe that people in general are trustworthy and fair") and a reputation system (saying "I believe that people with a good reputation are trustworthy and fair) are two different solutions for cooperation in a situation of information asymmetry. Generalized trust is manifested towards a person about whom nothing is known, based on the ability to estimate the trustworthiness of others. Thus, some individuals are more prone to manifest trust in different situations, either because they are born so either because of past experience (especially early interactions). Rotter (1967) distinguishes between people who have a high inclination to trust others in general and those with a low inclination to trust others in general [5]. If people in the first category will say "I will trust the other until I have evidence that he is untrustworthy" people in the second category will say: "I will not trust the other until I have clear evidence that he is trustworthy" (Rotter, 1967) [5]. The difference between these categories is given by the level of precautions.

Reputation refers to the register of previous actions of a specific person. Specific trust is based on reputation which is obtained by behaviour collected over time (Dasgupta, 1990) [2]. The more an individual is known to the person giving trust, the more the register of granting trust is consistent. But often, collaborative activities involve people who are not part of the close circle of acquaintances. In this case reputation needs other sources of accreditation, such as secondary evidence relating to reputation: stories, biographies, accounts of witnesses, resumes etc. In the case of the online auction websites, the visible reputation of a seller based on previous feedback from buyers is precisely this sort of alternative source of accreditation.

\section{LEVELS OF GENERALIZED TRUST IN ROMANIA AND THE NETHERLANDS}

Because we wanted to see to what extent the degree of generalized trust differs at macro level in Romania and the Netherlands, we carried out a secondary analysis using the database of the European Social Survey (ESS), the 2008 edition. In the following table we presented the three most frequently used items from the ESS for measuring levels of generalized trust.

\begin{tabular}{|c|c|c|c|c|}
\hline \multicolumn{2}{|l|}{ Country } & $\begin{array}{l}\text { Most people can be } \\
\text { trusted or you can't } \\
\text { be too careful }\end{array}$ & $\begin{array}{l}\text { Most people try to be } \\
\text { fair or try to take } \\
\text { advantage of you }\end{array}$ & $\begin{array}{c}\text { Most of the time people helpful } \\
\text { or mostly looking out for } \\
\text { themselves }\end{array}$ \\
\hline \multirow[t]{3}{*}{ Netherlands } & Media & 5,89 & 6,33 & 5,45 \\
\hline & Median & 6,00 & 7,00 & 6,00 \\
\hline & Total nr. of respondents & 1775 & 1776 & 1777 \\
\hline \multirow[t]{3}{*}{ Romania } & Mean & 3,79 & 3,67 & 3,36 \\
\hline & Median & 4,00 & 4,00 & 3,00 \\
\hline & Total nr. of respondents & 2129 & 2122 & 2117 \\
\hline
\end{tabular}

Tab. 1. Three measures of generalized trust from ESS 2008 [8] 


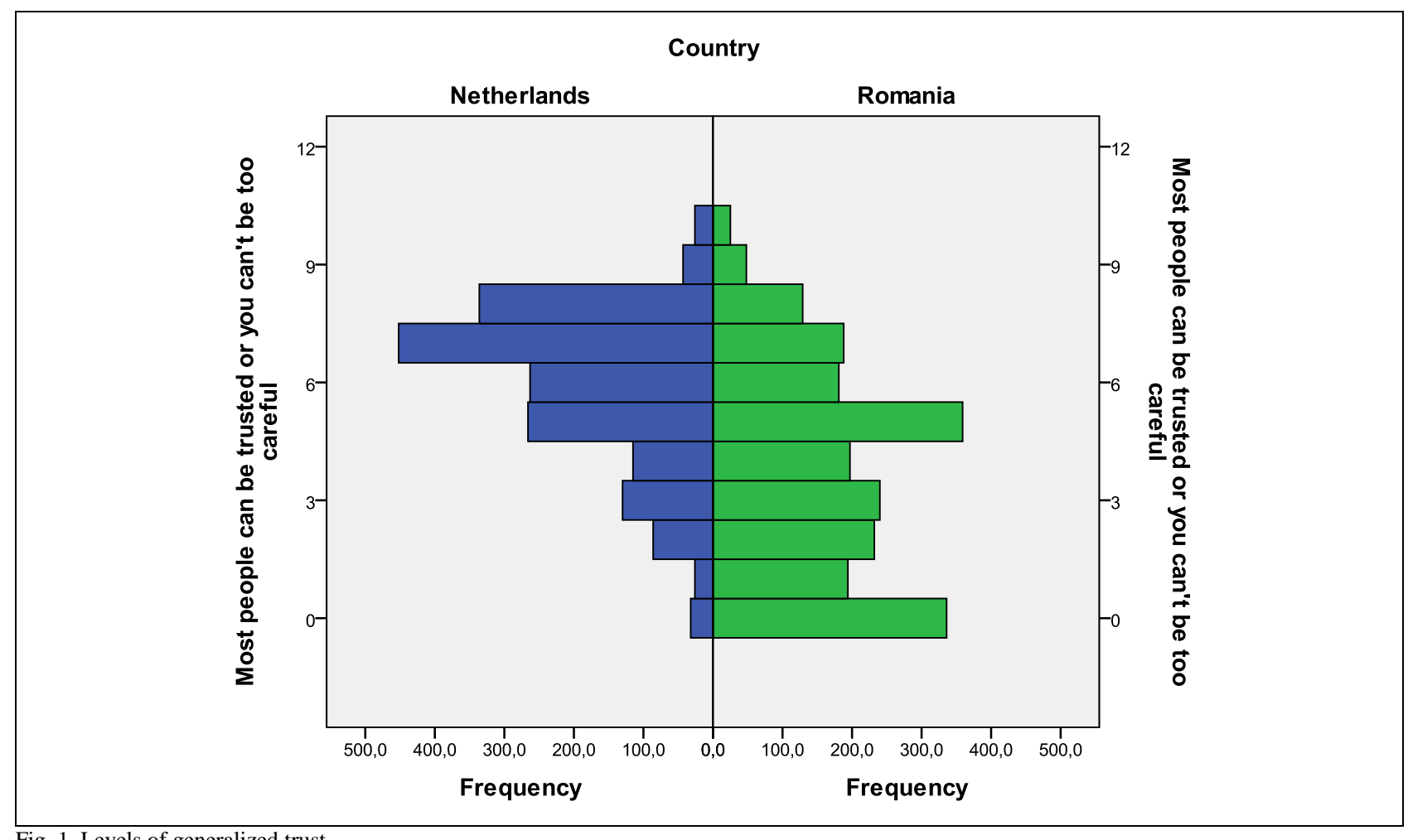

Fig. 1. Levels of generalized trust

The three items are measured on a scale from 1 to 10 , 1 representing the negative side of the scale (low trust) and 10 representing the positive side (high trust). The 10 steps scale can be considered as a continuous variable, thus the higher the mean and the median are for a country the higher the level of trust. Values under the value of 5 indicate a low manifestation of trust. The general orientation of the respondents from Romania are "You can't be too careful", "Most people try to take advantage of you" and "Most of the time people are looking out for themselves" while the Netherlands is situated at the other half of the scale, orientated towards the positive values of trust. The opposing orientations of generalized trust can be observed in Figure 1 above, where the most respondents from Romania are situated in the negative half of the scale (value 5 and below) and most respondents from the Netherlands are situated in the positive half of the scale (value 5 and above).

\section{A CASE STUDY OF REPUTATIONSYSTEMS VS. GENERALIZED TRUST IN ONLINE AUCTION WEBSITES.}

Generalized trust can also be observed in the behaviour of customers of online auction websites. Yamagishi \& Matsuda (2002) show that the use of a positive or a negative reputation system inside a (national) online auction website clearly indicates the level of generalized trust of the residents of that country [7]. In this sense, we want to underline the connection between the level of generalized trust in Romania and the Netherlands and the way the two most popular auction web-sites in these countries function as found in the online participatory observation conducted over a period of 8 months for the Netherlands and more than 12 months for Romania. Because in Romania we have a low generalized trust, a reputation system was developed to replace trust as the ensuring cooperation mechanism.
Online auction websites have millions of users worldwide, facilitating customer - to - customer (C2C) commerce. The individual wishing to sell a certain good opens a user account, uploads pictures of the respective good and its description, states a (starting) price and the delivery methods. These are roughly the basic characteristics of such auction websites.

In Romania the most popular auction website contains the features previously stated plus a series of characteristics referring to the reputation system. Each auction has a determined time span in which the buyer can auction. The buyer and the seller can enter in contact only through the website (e-mails and telephone numbers are not permitted to be seen by the website until the product is sold). The buyer receives the contact data of the seller only after he buys the product and the seller pays a percentage tax to the website for the sold product. The product is either (seldom) delivered in person (if the two live in the same city) or, in most cases, by post or currier. In this second and more often case, the buyer can evaluate the quality of the bought good only after he has paid for it risking therefore to purchase a "lemon". We can see this situation as one of information asymmetry, similar to the one described in the study of Kollock (1994) [3] about the second hand car market.

Every user (buyer or seller) has displayed the number of years / months he has been active on the website. But more importantly, each user receives a rating (which may be positive, neutral or negative) from his trading partner for each completed transaction. Therefore, at the end of each transaction, each partner receives a rating from the other, which emphasizes partners the satisfaction on how the trading proceeded. For the seller, this rating expresses the accuracy of the described product (whether he stated or not in description of the object eventual defects), the speed of answering questions, if he meet the delivery deadline and if he asked the originally announced price. 
For the buyer, the rating received from the seller often expresses whether or not he collected the good for which he made a bid. Over time, this system of ratings results in a "public reputation" of each participant which is useful for future potential trading partners to assess the extent in which a seller or a buyer is trustworthy. For example, a buyer is interested in purchasing an item from the "antiques" category. The buyer looks at the ratings which that seller received for his past transactions. He can have $100 \%$ positive ratings for his transactions across all categories or in the "antiques" category. This means that his previous buyers were all satisfied with his products and his services. In this case, the new buyer may find that the seller is trustworthy and decide to buy from him. If the seller has more negative ratings (for incorrect product description, hiding of any defects, price augmentation requested after the sale etc.) the buyer may decide not to complete the transaction with the seller for fear of purchasing a possible "lemon" or may choose to personally pick up the product in order to assess its quality (in the latter situation, however, transactions are restricted to localities where the buyer or seller can travel personally). Also, if the seller deletes an auction that already had bids (so if he changes his mind to sell the product) he receives a negative rating from the site administrators. Under these circumstances, we believe that the system favours the buyer.

However, as shown by Yamagishi \& Matsuda (2002), the role of negative reputation in these situations is relevant only if the system is a closed one (if participants cannot change their identity so as to erase a bad reputation) [7]. The role of reputation depends on the system type: if it is an open or a closed one. Closed systems operate as closed communities. Open systems involve exit and entry opportunities. In closed systems, negative reputation can be effective because it leads to the exclusion of those who violate community rules (Yamagishi \& Matsuda, 2002; Cook et al., 2005) [1], [7]. In open systems negative reputation is less efficient because it is known only to members directly connected in the network. Cook et al. (2005) concluded that negative reputation it is more effective than positive reputation in closed systems and positive reputation is better for building confidence in open systems as exclusion rules work better in closed groups than in open ones [1].

The online auction website represents an open system. In this case, a participant who has not been fair in previous transactions can create another account (another e-mail address and a different user name) to lose those negative ratings. But for a user who has already built a positive reputation in a long time it is disadvantageous to lose that reputation only in order to clear a possible negative rating. For such a user incentives to maintain his positive reputation and therefore only receive positive ratings are even higher. A reputation that an individual in trustworthy and fair is gained gradually over time but can be lost very quickly. He will therefore do his best so that he concludes transactions beneficial to both parties and continue having more buyers.

In the Netherlands, we analised the most popular auction website. In the open auction the starting price is displayed. Even though he received a number of offers, the seller can always change his mind and withdraw the product from sale without any penalty from the site administrators or from bidders. The seller has registered an e-mail to be contacted privately by bidders. Thus, a buyer can send a private message to the seller making an offer that it is not visible to other bidders.

The buyer first sends the money for the purchased product in the seller's bank account and the latter, after having verified that the transaction is complete, sends the product to the buyer by mail or by courier. There is no system of registration of a seller's reputation. In other words, for each transaction completed, there is no feedback rating on the account of the seller. The only way to signal reputation is the "seniority" that seller on website (the time since he enrolled on the website). The buyer must thus have much more trust in the seller, in a situation of pronounced information asymmetry. We consider thet this system can work due to the high generalized trust al country level.

\section{CONCLUSION}

In the case of the Romanian auction website, trust plays a limited role because formal mechanisms exist for ensuring cooperation. Or better said, because there is a very low generalized trust at country level, individuals use formal mechanisms, such as a public reputation system, to avoid opportunistic behaviour. In comparison with the one in the Netherlands, the online auction system from Romania has several mechanisms in order to discourage opportunistic behaviour and to ensure the protection of the buyer. The online auction system from the Netherlands requires a higher degree of general confidence from buyers, which confirms the data presented above about the generalized trust level in the two countries. In other words, we interpret these observations in the sense that based on a low generalized trust background in Romania, individuals who interact on auction website require a range of assurances such as public reputation while in the Netherlands, based on a higher level of generalized trust, transactions take place in the absence of such assurances.

\section{REFERENCES}

[1] Cook, K.; Hardin, R.; Levi, M. (2005), Cooperation without trust?,Russell Sage Foundation, ISBN 0-87154-164-5, New York

[2] Dasgupta, P. (1990), Trust as a commodity, In: Trust: Making and Breaking Cooperative Relations, Gambetta, D. (Ed.), Oxford Basil Blackwell

[3] Kollock, P. (1994), The emergence of exchange structures: an experimental study of uncertainty, commitment, and trust, The American Journal of Sociology, Vol. 100, No. 2., 1994

[4] Ouchi, W. (1979), A conceptual framework for the design of organizational control mechanisms, Management Science, Vol.25, No.9, 1979

[5] Rotter, J. (1967), A new scale for the measurement of interpersonal trust, Journal of Personality, Volume 35, Issue 4

[6] Yamagishi, T. (2011), Trust The Evolutionary Game of Mind and Society, Springer, ISBN 978-4-431-53935-3

[7] Yamagishi, T.; Matsuda, M. (2002), Improving the Lemons Market with a Reputation System: An Experimental Study of Internet Auctioning, Tech Rep May Hokkaido University

[8] ESS Round 4: European Social Survey Round 4 Data (2008). Data file edition 4.0. Norwegian Social Science Data Services 